ARTICLE

DOI: $10.1038 / \mathrm{s} 41467-017-01930-5$

\title{
Magnesium uptake by connecting fluid-phase endocytosis to an intracellular inorganic cation filter
}

Sandra H. Klompmaker ${ }^{1}$, Kid Kohl ${ }^{1}$, Nicolas Fasel ${ }^{1} \&$ Andreas Mayer (D $^{1}$

Cells acquire free metals through plasma membrane transporters. But, in natural settings, sequestering agents often render metals inaccessible to transporters, limiting metal bioavailability. Here we identify a pathway for metal acquisition, allowing cells to cope with this situation. Under limited bioavailability of $\mathrm{Mg}^{2+}$, yeast cells upregulate fluid-phase endocytosis and transfer solutes from the environment into their vacuole, an acidocalcisomelike compartment loaded with highly concentrated polyphosphate. We propose that this anionic inorganic polymer, which is an avid chelator of $\mathrm{Mg}^{2+}$, serves as an immobilized cation filter that accumulates $\mathrm{Mg}^{2+}$ inside these organelles. It thus allows the vacuolar exporter $\mathrm{Mnr} 2$ to efficiently transfer $\mathrm{Mg}^{2+}$ into the cytosol. Leishmania parasites also employ acidocalcisomal polyphosphate to multiply in their $\mathrm{Mg}^{2+}$-limited habitat, the phagolysosomes of inflammatory macrophages. This suggests that the pathway for metal uptake via endocytosis, acidocalcisomal polyphosphates and export into the cytosol, which we term EAPEC, is conserved.

\footnotetext{
${ }^{1}$ Department of Biochemistry, University of Lausanne, Ch. des Boveresses 155, CH-1066 Epalinges, Switzerland. Correspondence and requests for materials should be addressed to A.M. (email: andreas.mayer@unil.ch)
} 
D ioavailability of nutrient metals is commonly a limiting factor for microorganisms in their natural environment. This is especially the case for unicellular organisms with limited spatial motility such as yeast. Yeast species are found on plants and in soil ${ }^{1}$, habitats known to be rich in chelating agents like organic acids and tannins, which can limit the fraction of metal ions that are available for uptake across membranes ${ }^{2-5}$. Since plasma membrane metal transporters need free ions for uptake, mitigating strategies for metal acquisition in environments with low metal bioavailability would prove beneficial.

An effective strategy involves uptake of a metal-chelate across the plasma membrane and subsequent release of the metal in the cell. This mechanism has been described for iron and, more recently, zinc. Saccharomyces cerevisiae cells can acquire iron through ARN family plasma membrane transporters for siderophores that have been produced by other fungi or bacteria ${ }^{6-10}$. Pral was identified in the fungal pathogen Candida albicans as a "zincophore", a secreted protein sequestering zinc from the host cell in order to overcome nutritional immunity during invasive growth ${ }^{11}$. The intracellular fate of the metal-loaded siderophores and the mechanisms of metal release are not well described and depend on the type of siderophore and on the transporter involved. Arn1-mediated uptake of ferrichrome leads to its accumulation in the cytosol, where it showed slow iron release kinetics $^{12}$. Sit1-dependent internalization of ferrioxamine B leads to vacuolar storage after uptake ${ }^{13}$. C. albicans and Leishmania cells extract iron from host hemoglobin following endocytosis of the compounds and their degradation in lysosomes ${ }^{14,15}$.

Yeast vacuoles are acidocalcisome-like organelles that influence the equilibrium between metal supply and demand and are equipped with a vast number of transporters that load and discharge the organelle of polyphosphate (polyP), divalent metal ions and basic amino acids ${ }^{16-19}$. These features are shared across species with acidocalcisomes, lysosome-related organelles that are conserved from bacteria to $\operatorname{man}^{20}$. The cellular functions of acidocalcisomes are poorly understood. Like yeast vacuoles, they are regarded as storage compartments for metal cations and phosphate, which they accumulate to high concentrations ${ }^{21}$. PolyP is a ubiquitous inorganic polymer that is present in all kingdoms of life. It consists of long chains of inorganic phosphate units linked by phosphoric anhydride bonds. PolyP efficiently chelates divalent metal ions ${ }^{22}$ but interacts also with other acidocalcisomal cations such as spermidine and basic amino acids $^{23,24}$. PolyP is implicated in pathogenicity of bacteria and parasites $^{25,26}$ and in blot clotting in mammals ${ }^{27}$. In lower eukaryotes, polyP is synthesized by the polyphosphate polymerase Vtc4, a component of the membrane-anchored vacuolar transporter chaperone (VTC) complex, which consists of the subunits Vtc1 through Vtc5 ${ }^{28,29}$. Cells lacking polyP show increased resistance to $\mathrm{Ni}^{2+}, \mathrm{Cd}^{2+}$ and $\mathrm{Mn}^{2+}$ stress ${ }^{30,31}$, whereas mutants with increased polyP levels, such as pho80 $\Delta$, are hypersensitive to high concentrations of $\mathrm{Mn}^{2+}$ and $\mathrm{Co}^{2+32}$.

Here we investigate how Saccharomyces cerevisiae copes with limited bioavailability of metal ions, mimicking this situation by growing the cells in medium with EDTA. We find that upregulation of fluid-phase endocytosis under these conditions leads to increased transfer of extracellular solutes to the vacuole, where metal ions are accumulated and then exported into the cytosol.

\section{Results}

PolyP-deficient cells are sensitive to low metal availability. Cells lacking polyP and the vacuolar polyP polymerase VTC show normal growth in standard rich media such as YPD (Fig. 1a). When the bioavailability of divalent metal ions was reduced by addition of the chelator EDTA, wild-type cells only reduced their growth rate (Fig. 1b), whereas cells lacking VTC subunits ( $v t c 1 \Delta$, $v t c 4 \Delta)$ arrested growth. Cells expressing Vtc $4^{\mathrm{R} 264 \mathrm{~A}}$, an active-site mutant that allows the assembly of an intact yet inactive VTC complex, displayed the same growth phenotype ${ }^{28} \cdot v t c 3 \Delta$ cells a
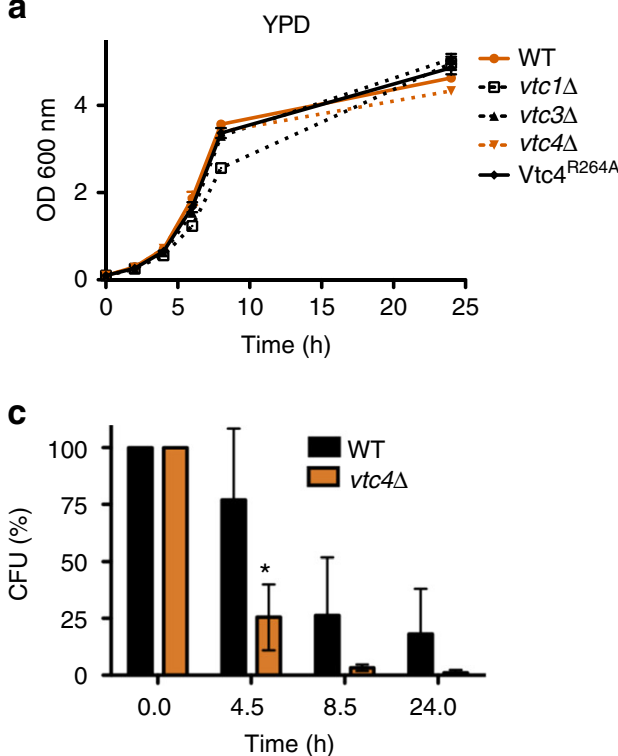

b

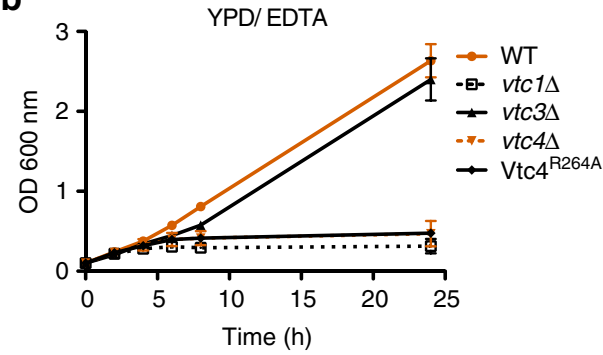

d

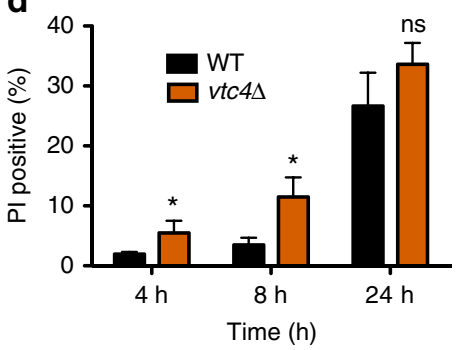

Fig. 1 Growth and survival of wild-type and vtc $4 \Delta$ cells. Cells were grown (a) in liquid YPD or (b) in YPD supplemented with 1 mM EDTA and the OD $600 \mathrm{~nm}$ was determined at the indicated times. c Capacity to form colonies. Cells were grown on YDP/EDTA for the indicated periods of time, cell density was determined, and equal numbers of cells were withdrawn and plated on solid YPD plates. Colony-forming units (CFU) were counted after 2 days of incubation at $30^{\circ} \mathrm{C}$. $\mathbf{d}$ Live/dead cell staining. Wild-type and vtc $4 \Delta$ cells were collected from YPD/EDTA cultures and stained with propidium iodide (PI) at the indicated time points. The fraction of dead cells in the population was determined by flow cytometry. Differences were evaluated using Student's $t$ test comparing vtc $4 \Delta$ and wild-type values at the respective time points; ns, non-significant; ${ }^{\star} p \leq 0.05$. The results represent the mean $\pm S D$ of 3 (a, $\mathbf{b}$, d) or 5 (c) independent experiments 


\section{a}

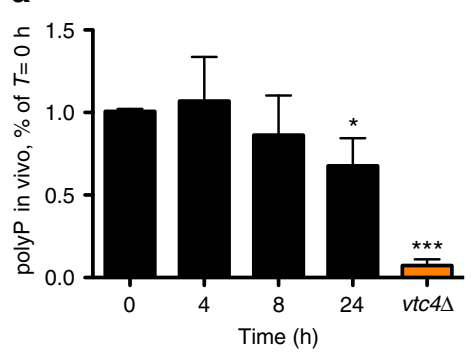

b

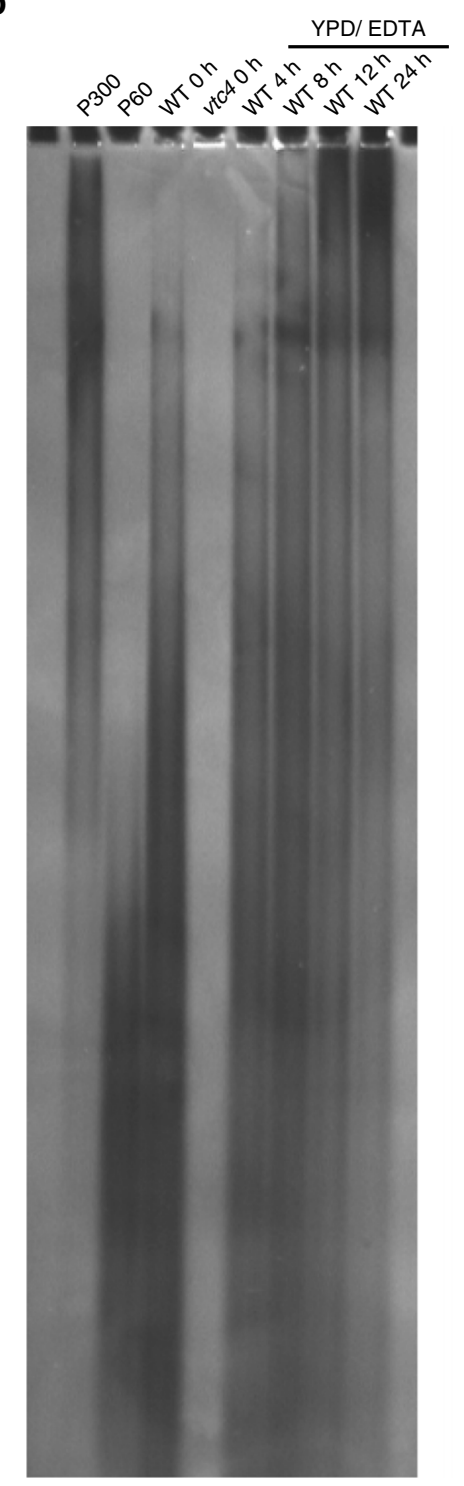

d

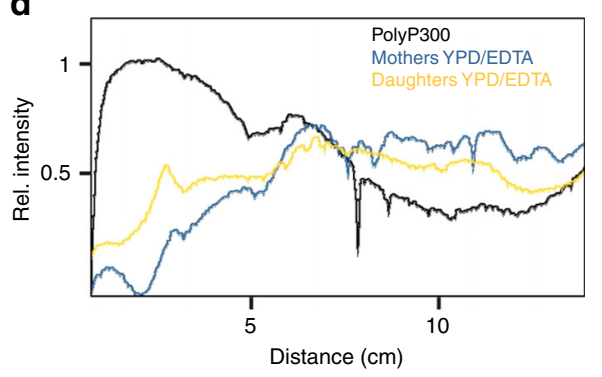

C

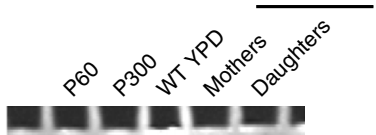

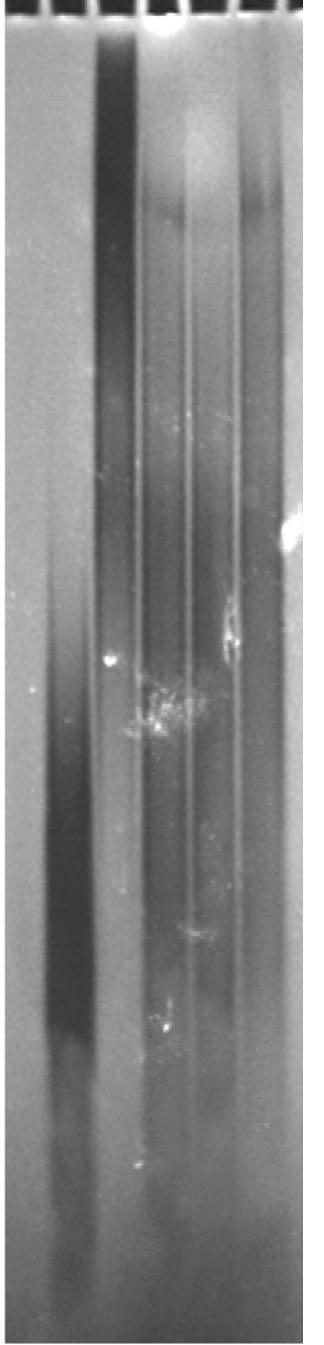

Fig. 2 Amounts and chain length of polyP on YPD/EDTA. a PolyP content in wild-type cells on YPD/EDTA. Cells were grown on YPD/EDTA for the indicated periods of time, collected, and polyP content was assayed. Results represent mean \pm SD of three independent experiments. Statistical differences were determined using Student's $t$ test comparing polyP levels from $T=0 \mathrm{~h}$ with the later time points and the $v t c 4 \Delta$ strain; ${ }^{\star} p \leq 0.05$; ${ }^{\star \star \star} p \leq 0.001$. $\mathbf{b}$ Chain length. PolyP was extracted from cells growing on YPD/EDTA for the indicated periods of time. PolyP was purified from cells by glass bead rupture and phenol/chloroform extraction. Samples were treated with RNAse A and proteinase K before $30 \mathrm{nmol}$ of polyP were resolved on a $15 \%$ polyacrylamide gel, followed by negative staining with DAPI. c Mother $(\mathrm{m})$ and daughter $(\mathrm{d})$ fractions were separated after $16 \mathrm{~h}$ of growth on YPD/EDTA. PolyP was extracted from cells as in (b), resolved on a $20 \%$ polyacrylamide gel and stained with DAPI. PolyP isolated from a non-separated population of wild-type cells growing logarithmically on YPD is shown for comparison. $\mathbf{d}$ The signal intensity in the lanes with mother and daughter samples from (c) was quantified using ImageJ, starting at the top of the gel. The profile for polyP300 was included for comparison 
grew like wild-type because Vtc3 can be substituted for by its homolog $\mathrm{Vtc} 2^{28,33}$. The vast majority of polyP in $S$. cerevisiae is stored in the vacuole. However, polyP is a cell wall component in a large variety of fungi, and in $S$. cerevisiae evidence for and against a cell wall fraction was presented ${ }^{34-38}$. Since a portion of the VTC complex localizes to the cell periphery ${ }^{33}$, where it could potentially synthesize polyP for transfer into the periplasm, we analyzed the localization of GFP-tagged Vtc4 under metal limitation (Supplementary Fig. 1). Vacuolar localization was confirmed by co-localization with the marker dye FM4-64. On metalreplete YPD, the majority of GFP-Vtc4 localized to the vacuole but a significant portion was found at the cell periphery. On YPD/ EDTA, GFP-Vtc4 disappeared from the cell periphery and localized exclusively to the vacuole and vacuole-associated vesicles. This observation argues against a role of the peripheral pool of VTC in metal acquisition and suggests that vacuolar rather than cell wall-associated polyP supports growth under metal limitation.

Cells experiencing starvation conditions may either die or arrest the cell cycle. We distinguished between these possibilities by subjecting cells to different periods of metal starvation on YPD/EDTA, followed by plating on metal-replete YPD medium to measure the number of colony-forming units (CFU) (Fig. 1c). During the first $4 \mathrm{~h}$ of adaptation to metal limitation, the number of colony-forming units of wild-type cells dropped to $75 \%$ of the initial value, that of $v t c 4 \Delta$ cells was reduced to $25 \%$. We tested for the presence of dead cells by propidium iodide (PI) staining and flow cytometry (Fig. 1d). Propidium iodide is excluded from living cells but brightly stains dead cells, which lose metabolic activity that is required to maintain the selective permeability barrier of the plasma membrane. $3 \%$ of wild-type cells were PIpositive after $8 \mathrm{~h}$ in YPD/EDTA. Only $12 \%$ of $v t c 4 \Delta$ cells stained with PI at this time point, even though the number of CFUs for this strain had declined by $>95 \%$ over the same period. Prolonged exposure to EDTA for $24 \mathrm{~h}$ killed $25 \%$ of wild-type cells, but the survivors retained their capacity to form colonies, which was not the case for $v t c 4 \Delta$ cells. Thus, a large fraction of polyP-deficient $v t c 4 \Delta$ cells $^{39}$ remain alive and metabolically active in YPD/ EDTA, but they rapidly arrest growth. This suggests that polyP is necessary to preserve the capacity of cells to divide on YPD/ ETDA.

PolyP changes under limited metal bioavailability. On medium with limiting amounts of zinc, yeast cells grow linearly instead of exponentially ${ }^{40}$. This is due to the fact that mothers born on rich media continue dividing, whereas newly born daughters arrest growth in the G1 phase of the cell cycle. We observed the same behavior for wild-type yeast cells grown on YPD/EDTA (Supplementary Fig. 2). Given that polyP is crucial for growth on YPD/EDTA, we analyzed changes of polyP under these conditions. Time-course analysis showed that wild-type cells maintained their polyP levels on YPD/EDTA (Fig. 2a). PolyP chain length distribution was examined by gel electrophoresis and negative staining of the gel with DAPI. YPD-grown wild-type cells $(T=0 \mathrm{~h})$ contained mostly polyP of 60-100 residues (Fig. 2b). On YPD/EDTA, long-chain polyP of $>300$ residues increased strongly. After $24 \mathrm{~h}$ of growth, the majority of the population consisted of non-dividing daughter cells. These are readily identifiable due to the fact that they carry only a single bud scar, a cell wall remnant from a preceding cell division that can be stained with Calcofluor white. In order to test whether poly $\mathrm{P}$ differed in dividing mothers and arrested daughters, we separated these two fractions. The inoculum (mothers) was crosslinked to biotin-fluorescein, washed and cultivated for $16 \mathrm{~h}$ on YPD/EDTA. Mothers and daughters were separated by purification with streptavidin-coated, magnetic Dynabeads, which adsorb preferentially biotin-labeled mothers. Fraction purity was assessed microscopically by counting fluorescein-positive and -negative cells. The mother fraction contained $35-45 \%$ of daughters, largely due to daughters that had not yet completed cytokinesis and separated from the mothers. Daughter fractions contained $<10 \%$ mother cells. PolyP from daughter cells contained a higher amount of long-chain polyP, whereas short and intermediate polyP chains dominated in the mother fraction, especially if one takes into consideration that a large part of the long-chain polyP visible in the mother fraction must originate from its inevitable $35 \%$ contamination with daughter cells (Fig. 2c). If vacuolar polyP degradation is impaired, vacuoles accumulate extremely long polyP chains of $>300$ residues ${ }^{41}$. Together with the fact that also the purified catalytic domain of the complex synthesizes very long-chain poly $\mathrm{P}^{28}$, this suggests that VTC is a highly processive enzyme. The presence of shorter chains in YPD/EDTA-grown mothers can then be taken as an indication of turnover of polyP by polyphosphatases. Since only the mothers divide on YPD/EDTA, whereas daughters do not, growth on YPD/EDTA coincides with and might require polyP turnover.

$\mathrm{Mg}^{2+}$ limits growth of polyP-deficient cells on YPD/EDTA. Since EDTA chelates a range of divalent metal ions, we asked which metal restricts growth of polyP-deficient strains. Cells were pre-cultured on YPD and then cultivated in YPD/EDTA for different periods of time before metal levels were determined by inductively-coupled plasma (ICP)-MS analysis. The metal content per cell decreased over time for $\mathrm{Fe}, \mathrm{Zn}$, and $\mathrm{Mn}$, with no major differences between wild-type and $v t c 4 \Delta$ cells (Fig. 3a). This suggests that cells grew by using, at least partially, stores of these metals that are independent of polyP. Wild-type cells stabilized the levels of $\mathrm{Mg}, \mathrm{Cu}$, and $\mathrm{Ca}$ at $35-50 \%$ of the initial value (Fig. 3a). vtc $4 \Delta$ cells showed similar stabilization for $\mathrm{Cu}$ and $\mathrm{Ca}$, but their content of $\mathrm{Mg}$ kept decreasing to $<10 \%$ over $24 \mathrm{~h}$ (Fig. 3a). Even on YPD without EDTA $(T=0 \mathrm{~min}), v t c 4 \Delta$ cells had $40 \%$ less $\mathrm{Mg}$ than wild-type cells. This suggests that wild-type cells extract enough $\mathrm{Mg}, \mathrm{Ca}$, and $\mathrm{Cu}$ from YPD/EDTA to allow them to stabilize their content of these three ions. However, the stabilization of $\mathrm{Mg}$ levels depends on polyP.

This picture was corroborated by integrating the metal content over all the cells in the culture, which allows to assay the net transfer of metals from the medium into the sedimentable, living material. Whereas cell-associated $\mathrm{Mg}$ and $\mathrm{Ca}$ increased in the pellets of wild-type cultures more than 20 -fold over $24 \mathrm{~h}$ on YPD/ EDTA (Fig. 3b), other metals showed no (Zn) or only moderate increases of $<5$-fold $(\mathrm{Mn}, \mathrm{Cu}, \mathrm{Fe}) . \mathrm{Ca}^{2+}$ levels reproducibly spiked after $4 \mathrm{~h}$ (Fig. 3b), which might be due to activation of the calcineurin/ Crzl pathway, which strongly augments $\mathrm{Ca}^{2+}$ uptake $^{42}$. Apart from a moderate increase in $\mathrm{Cu}, v t c 4 \Delta$ cultures did not accumulate any of the tested metals, which reflects their lack of growth on EDTA.

On the basis of these results, we hypothesized that EDTA might limit growth of cells by reducing the bioavailability of $\mathrm{Mg}^{2}$ ${ }^{+}$. In order to test this, we depleted cellular metal pools by incubating the cells in YPD/EDTA for $5 \mathrm{~h}$ (Fig. 3c). Subsequently, cells were diluted into YPD that had been depleted of metals by chromatography over a Chelex ion-exchange matrix, which reduced the $\mathrm{Mg}$ content of this medium to $10 \mu \mathrm{M}$ (determined by ICP-MS). This medium was then supplemented with a single metal at a time. Only addition of $\mathrm{Mg}^{2+}$ allowed cells to proliferate and the response was similar for wild-type and $v t c 4 \Delta$ cells. This suggests that cells grown on YPD/EDTA do not maintain a sufficiently large stock of $\mathrm{Mg}^{2+}$ to support further cell divisions 

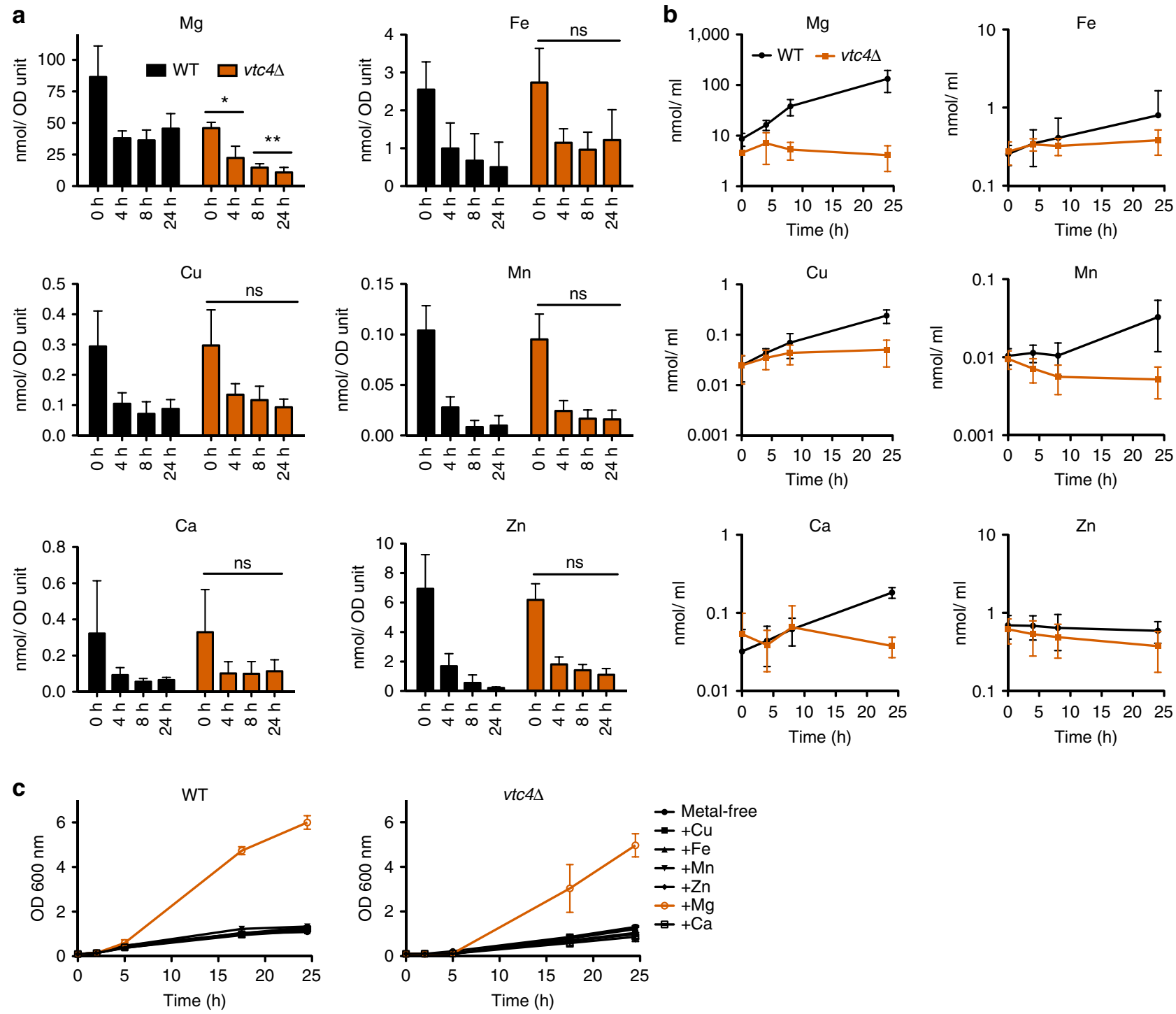

Fig. 3 Metal extraction from YPD/EDTA. Time-course ICP-MS analysis. Cells were pre-cultured on YPD and transferred to YPD/EDTA. At the indicated time points, aliquots were withdrawn, cell density was determined, the cells were sedimented and their content of magnesium, iron, zinc, copper, manganese and calcium was measured. a Values per $\mathrm{OD}_{600 \mathrm{~nm}}$ unit of cells and (b) the values per culture volume, which allows to judge whether there is net transfer of metal from the medium into the accumulating biomass. $\mathbf{c}$ Growth on YPD/Chelex medium. Wild-type and vtc $4 \Delta$ cells were pre-cultured for $5 \mathrm{~h}$ on YPD/EDTA and transferred to YPD/Chelex medium supplemented with the indicated metal to final concentrations that are sufficient to support vigorous continuous growth of non-depleted wild-type cells: $0.25 \mu \mathrm{M} \mathrm{CuSO}_{4} ; 1.2 \mu \mathrm{M} \mathrm{FeCl}_{3} ; 2.6 \mu \mathrm{M} \mathrm{MnSO}_{4} ; 2.5 \mu \mathrm{M} \mathrm{ZnSO} 4 ; 0.9 \mathrm{mM} \mathrm{CaCl}$; $4.2 \mathrm{mM}$ $\mathrm{MgSO}_{4}$. The $\mathrm{OD}_{600 \mathrm{~nm}}$ was measured at the indicated time points after transfer. a-c Results represent mean $\pm \mathrm{SD}$ of at least three independent experiments. Statistical differences in a were determined using Student's $t$ test comparing $v t c 4 \Delta$ and wild-type cells at each time point; ${ }^{*} p \leq 0.05$; ${ }^{\star *} p \leq 0.005$

under $\mathrm{Mg}^{2+}$ limitation. Therefore, their growth on YPD/EDTA depends on continuous extraction of $\mathrm{Mg}^{2+}$ from this medium.

A vacuolar $\mathrm{Mg}^{2+}$ exporter is required for $\mathrm{Mg}^{2+}$ uptake. Several intracellular pools of $\mathrm{Mg}^{2+}$ exist, with transporters and channels controlling the fluxes between them. Alr1 mediates the majority of $\mathrm{Mg}^{2+}$ uptake at the plasma membrane ${ }^{43}$. Cells lacking Alr1 depend on supplementation of their media with high concentrations of $\mathrm{Mg}^{2+}$ for wild-type-like growth. Overexpression of its homolog Alr2 can rescue this phenotype ${ }^{43,44}$. The Mrs2/ Mfm1 complex controls $\mathrm{Mg}^{2+}$ import into mitochondria ${ }^{45,46}$ and Mmel exports $\mathrm{Mg}^{2+}$ from this organelle ${ }^{47}$. A vacuolar $\mathrm{Mg}^{2+}$ importer has not been identified, but Mnr2 mediates efflux of $\mathrm{Mg}^{2+}$ from vacuoles ${ }^{48}$.
In order to test whether a particular intracellular $\mathrm{Mg}^{2+}$ pool is essential for cells to grow on metal-limiting medium, we assayed knockout strains for these $\mathrm{Mg}^{2+}$ transporters for growth on YPD/ EDTA (Fig. 4a, b). Cells lacking the plasma membrane transporter Alr1 grew only slowly on YPD and did not grow on YPD/EDTA (Fig. 4b). Alr2s, $m r s 2 \Delta, m f m 1 \Delta$, and $m m e 1 \Delta$ strains grew like wild-type cells on both media. Interestingly, $m n r 2 \Delta$ cells mimicked the phenotype of a $v t c 4 \Delta$ strain. They rapidly ceased growth on YPD/EDTA but grew like wild-type on YPD (Fig. 4a). By contrast, mutants for other known vacuolar metal exporters such as $\mathrm{zrt3} \Delta\left(\mathrm{Zn}^{2+}\right), \mathrm{y} v c 1 \Delta\left(\mathrm{Ca}^{2+}\right), \operatorname{ctr} 2 \Delta\left(\mathrm{Cu}^{2}\right.$ $\left.{ }^{+}\right)$, and fth $1 \Delta\left(\mathrm{Fe}^{2+}\right)$ grew like wild-type (Fig. 4c). Only smf $3 \Delta$ $\left(\mathrm{Fe}^{2+}\right)$ cells showed slightly reduced growth kinetics. This suggests that growth on YPD/EDTA specifically requires the vacuolar $\mathrm{Mg}^{2}$ + exporter Mnr2. Furthermore, ICP-MS analysis showed that, 
a

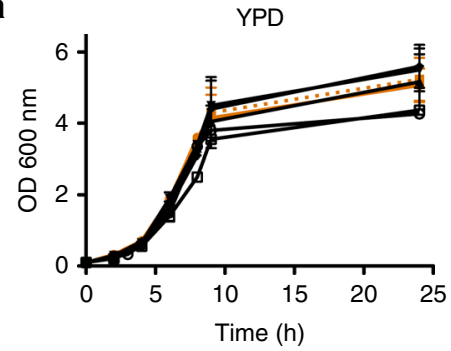

b

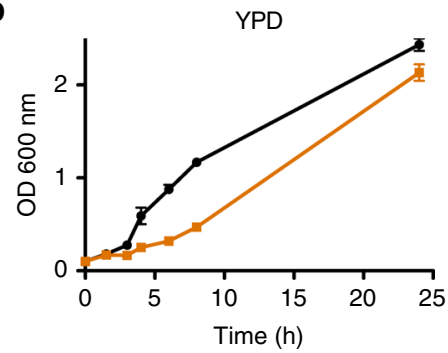

C

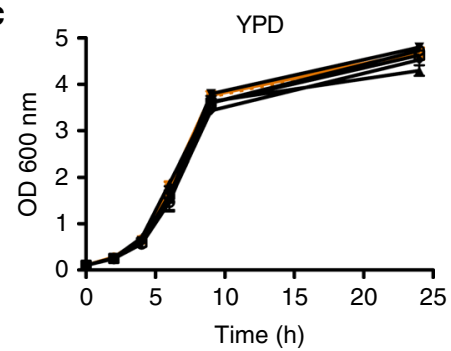

d

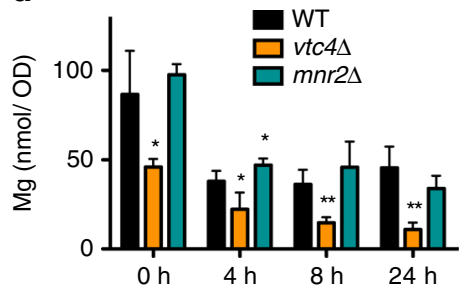

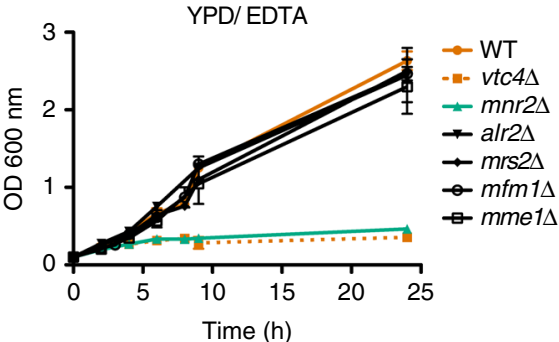

YPD/ EDTA
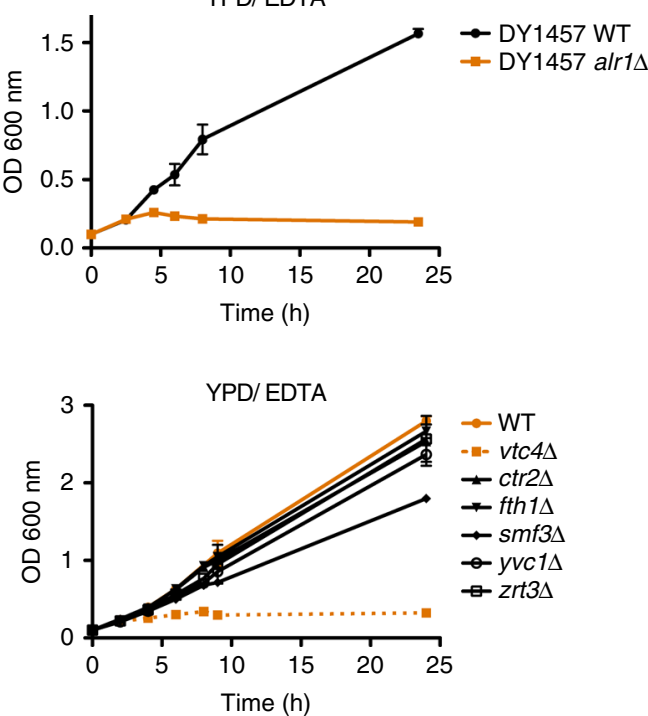
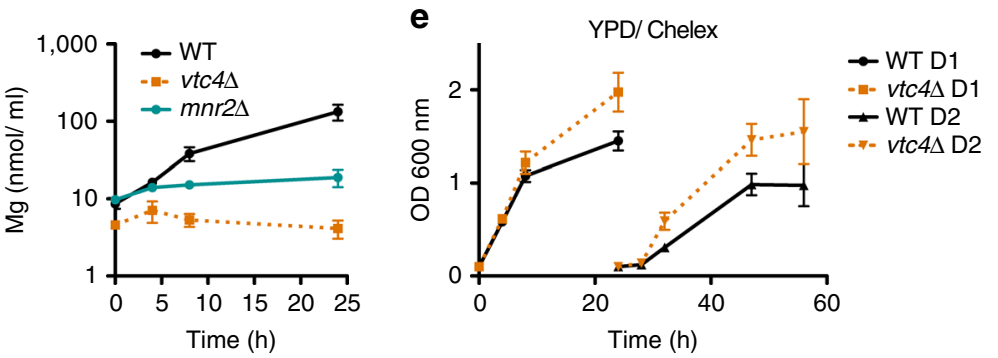

Fig. 4 Role of metal transporters for growth on YPD/EDTA. a Magnesium transporter mutants were pre-cultured on YPD, transferred to YPD or YPD/ EDTA, and the $\mathrm{OD}_{600 \mathrm{~nm}}$ was measured at the indicated times after transfer. b Growth of alr1s cells was assayed as in (a). c Growth of vacuolar metal exporter mutants was assayed as in (a). d Time course ICP-MS analysis of the magnesium content of mnr2 $\Delta$ cells at the indicated times after transfer from YPD to YPD/EDTA. Values per cell and per culture volume are shown. Note that the values for wild-type and vtc $4 \Delta$ are the same as in Fig. $3 b$ because mnr2 $\Delta$ cells had been tested as part of the same experiments. e Growth of wild-type and vtc $4 \Delta$ cells on Chelex-treated YPD. Cells were pre-cultivated in YPD, washed and transferred to YPD/Chelex. The $\mathrm{OD}_{600 \mathrm{~nm}}$ was followed for one day (D1). The cells were then re-inoculated in fresh YPD/Chelex and growth was followed for another day (D2). The results represent mean \pm SD of at least three independent experiments. Differences in $\mathbf{d}$ were evaluated using Student's $t$ test comparing vtc $4 \Delta$ and $m n r 2 \Delta$ cells with wild-type cells at each time point; ${ }^{*} p \leq 0.05 ;{ }^{\star \star} p \leq 0.01$

similarly as $v t c 4 \Delta$ cells, $m n r 2 \Delta$ cells did not efficiently accumulate $\mathrm{Mg}$ from the growth medium (Fig. 4d, right panel). However, $m n r 2 \Delta$ cells did not show the decrease in $\mathrm{Mg}$ content that was observed in $v t c 4 \Delta$ cells, showing that $m n r 2 \Delta$ cells could not mobilize their vacuolar $\mathrm{Mg}$ when needed (Fig. $4 \mathrm{~d}$, left panel).

These results suggest that both uptake of $\mathrm{Mg}^{2+}$ through the plasma membrane and mobilization of $\mathrm{Mg}^{2+}$ from vacuoles contribute to growth on YPD/EDTA. This is in line with the observation that $v t c 4 \Delta$ cells grow even slightly better than wildtype on Chelex-treated medium, which is low in $\mathrm{Mg}^{2+}$, but in which this $\mathrm{Mg}^{2+}$ is fully bioavailable and thus accessible to the plasma membrane transporters Alr1 and Alr2 (Fig. 4e). Under these conditions, plasma membrane uptake can apparently satisfy the $\mathrm{Mg}^{2+}$ requirements for growth. By contrast, growth under conditions of limited bioavailability requires vacuolar polyP and vacuolar $\mathrm{Mg}^{2+}$ export.

$\mathrm{Mg}^{2+}$ uptake requires fluid-phase endocytosis and retrograde traffic. Given that polyP, which is enclosed in vacuoles, facilitated $\mathrm{Mg}^{2+}$ uptake into the cytosol, we explored how $\mathrm{Mg}^{2+}$ could be brought in contact with polyP and tested fluid-phase endocytosis as a possibility. We quantified this process using the fluorescent fluid-phase endocytosis marker Lucifer yellow ${ }^{49}$. Cells were grown on YPD and YPD/EDTA for 2 and $6.5 \mathrm{~h}$ before adding Lucifer yellow and incubating them for an additional hour. The cells were sedimented and washed. Dye uptake was analyzed qualitatively by fluorescence microscopy (Fig. 5a) and quantified 
by flow cytometry (Fig. 5b). Both wild-type and $v t c 4 \Delta$ cells showed significantly higher Lucifer yellow fluorescence after $3 \mathrm{~h}$ of growth in YPD/EDTA when compared to YPD. This difference increased further after $7.5 \mathrm{~h}$ on YPD/EDTA, suggesting that the cells had upregulated their capacity for fluid-phase endocytosis as a consequence of limited metal availability.

We tested the growth effects of mutations perturbing fluidphase endocytosis (sac6s, vrp1 1 , end $3 \Delta, \operatorname{arc18\Delta }, \operatorname{sla} 1 \Delta)$, vacuolar protein sorting at the endosome ( $v p s 4 \Delta)$, and autophagy (atg8s, Fig. 5c). Wild-type and atg8 $\Delta$ cells showed robust growth during $24 \mathrm{~h}$ of incubation on YPD/EDTA. In contrast, cells lacking components of the endocytic machinery mimicked the growth defect of polyP-deficient cells. $v p s 4 \Delta$ cells displayed an intermediate growth phenotype. ICP-MS analysis of the endocytosis mutants $\operatorname{sac} 6 \Delta$ and $\operatorname{vrp} 1 \Delta$ confirmed their defects in $\mathrm{Mg}^{2+}$ acquisition (Fig. 5d). Continuous uptake of $\mathrm{Mg}^{2+}$ should

a

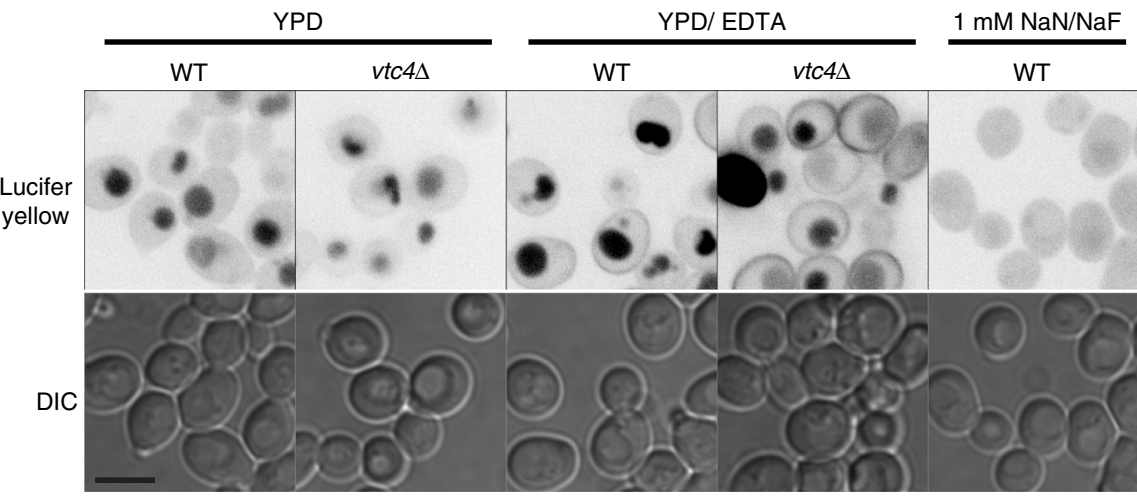

b
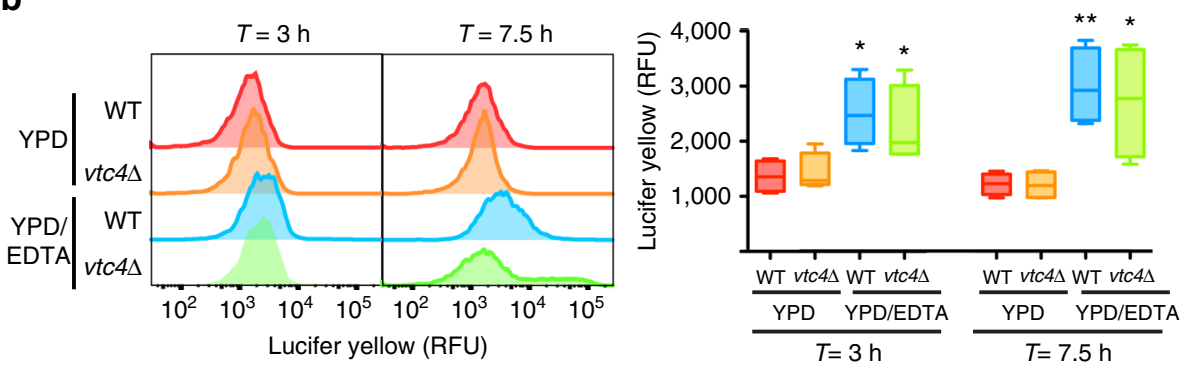

C
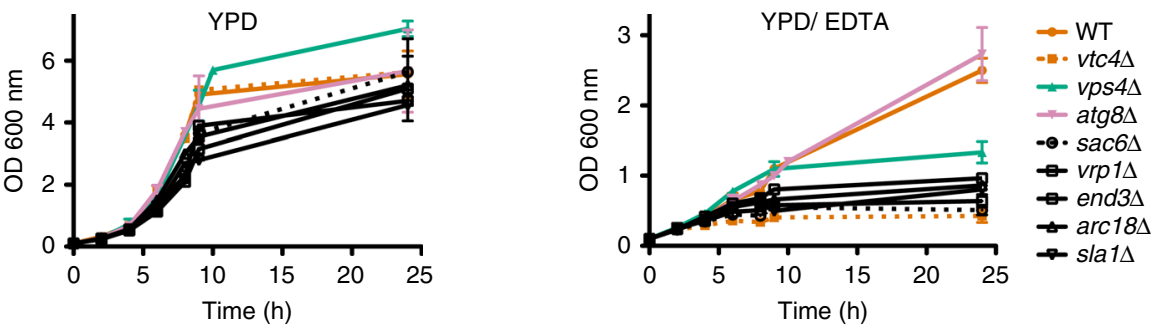

d
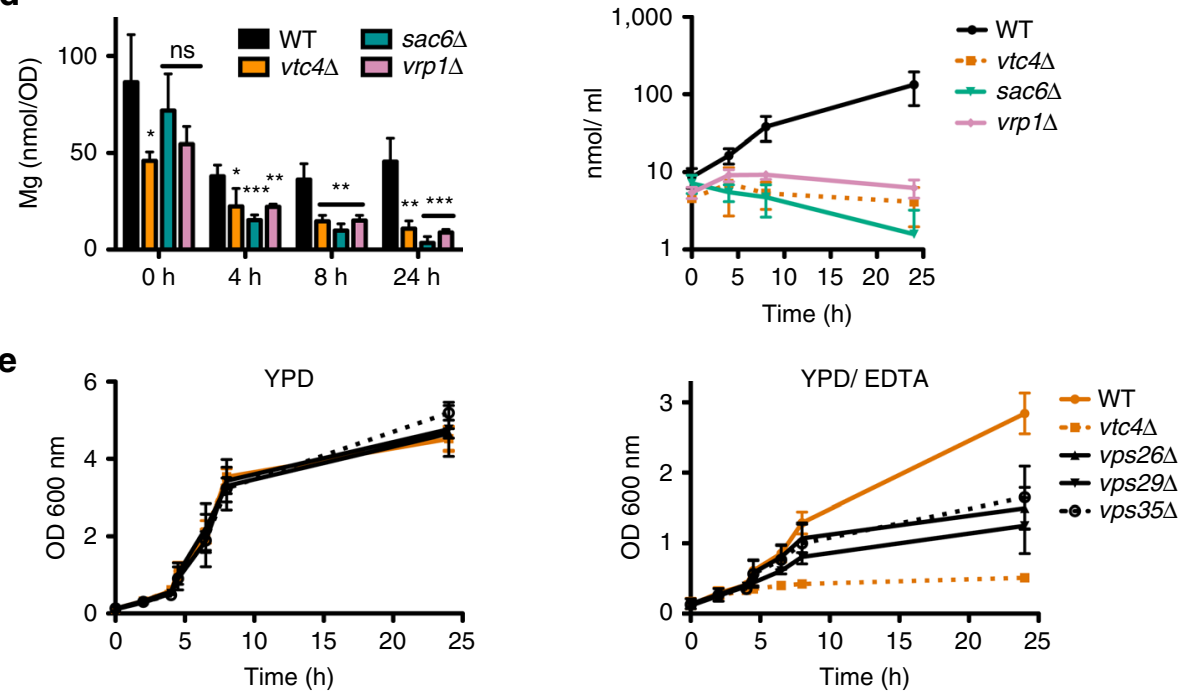
necessitate a compensatory fluid exit from vacuoles in order to allow extrusion of non-used compounds that had been taken up through fluid-phase endocytosis. In line with this, mutants in the Retromer complex ( $v p s 35 \Delta, v p s 29 \Delta, v p s 26 \Delta)$, which mediates vesicular exit from endosomes and vacuoles ${ }^{50-52}$, showed similar growth defects on EDTA as the endocytosis mutants (Fig. 5e). Taken together, these observations support a model in which limited bioavailability of $\mathrm{Mg}^{2+}$ prompts cells to upregulate fluidphase endocytosis in order to deliver extracellular ions into the vacuole. The polyP that is accumulated in this compartment is a strong chelator for $\mathrm{Mg}^{2+22,23}$, which probably enables the cell to retain the endocytosed $\mathrm{Mg}^{2+}$. Finally, $\mathrm{Mg}^{2+}$ is transferred from the vacuolar lumen to the cytosol via the dedicated $\mathrm{Mg}^{2+}$ exporter Mnr2.

PolyP is needed in $\mathrm{Mg}^{2+}$-poor environments across species. We sought to test whether polyP in acidocalcisome-like organelles might act similarly in a more physiological setting and whether its requirement for $\mathrm{Mg}^{2+}$ acquisition might be conserved in evolution. To this end, we utilized macrophages, which phagocytose pathogens and finally degrade them. Some pathogens, however, evade or resist digestion and even multiply within the phagolysosomes, subverting the host cell machinery to proliferate. Access to nutrients and specifically to $\mathrm{Mg}^{2+}$ is limited within the phagosome ${ }^{53-56}$. We utilized the trypanosomatid parasite Leishmania major as a model. Trypanosomatids contain acidocalcisomes that share polyP and many transporters with yeast vacuoles $^{57}$. After entering the mammalian host, Leishmania is taken up by macrophages, where it resides and proliferates in the phagolysosome ${ }^{58}$. Growth in these phagolysosomes is limited by $\mathrm{Mg}^{2+59}$. We tested for a potential role of polyP by creating a homozygous deletion mutant of $L$. major VTC4 and a rescued version of this cell line (VTC4 $2 \mathrm{~S}$ ), in which a functional VTC4 allele was re-integrated into the genome of the homozygous deletion mutant ${ }^{60}$ (Supplementary Figs. 3 and 4 ). In order to assess polyP synthesis, we cultivated the promastigote form of the parasites and quantified their polyP using the fluorescent indicator DAPI, which generates a characteristic emission at $550 \mathrm{~nm}$ (Fig. 6a). PolyP of wild-type and VTC4 2S cells peaked during logarithmic growth, whereas no polyP was detected in $v t c 4 \Delta / v t c 4 \Delta$ cells. Equivalent results were obtained by assaying polyP through enzymatic hydrolysis and quantification of the released $\mathrm{P}_{\mathrm{i}}$ (Supplementary Fig. 5). Next, we infected bone marrow-derived mouse macrophages with these strains for $6 \mathrm{~h}$. Non-phagocytosed parasites were washed away and the number of Leishmania cells per macrophage was counted 24,48 , and $72 \mathrm{~h}$ after infection (Fig. 6b). The rate of phagocytosis was similar for all cell lines, illustrated by a similar parasite load of 2-3 parasites per macrophage after $24 \mathrm{~h}$. However, the number of $v t c 4 \Delta / v t c 4 \Delta$ parasites per macrophage did not increase over the next two days, whereas wild-type and VTC4 $2 \mathrm{~S}$ cell numbers doubled in the phagolysosomes and reached a concentration of 5-7 parasites per macrophage. Thus, polyP is necessary for intracellular replication of Leishmania in the $\mathrm{Mg}^{2+}$-poor environment of the phagolysosome.

\section{Discussion}

Our data identify a novel pathway for acquiring $\mathrm{Mg}^{2+}$ by fluidphase endocytosis. Under limited metal bioavailability, the cells upregulate endocytosis in order to bring soluble metals into their acidocalcisome-like, polyP-loaded vacuole. Our results suggest that uptake via this EAPEC pathway and plasma membrane transport are not mutually exclusive but rather complementary. When $\mathrm{Mg}^{2+}$ is scarce but fully bioavailable, a condition that we mimicked through $\mathrm{Mg}^{2+}$-depleted but EDTA-free medium, the high-affinity $\mathrm{Mg}^{2+}$-transporters in the plasma membrane suffice to support growth. The endocytosis/polyP-dependent EAPEC route becomes essential for growth when bioavailability is low, enabling the cell to cope with this condition, which is often encountered in natural settings 5 .

PolyP avidly binds numerous divalent metal ions and readily forms gels with them ${ }^{23}$. PolyP accumulates in acidocalcisome-like vacuoles to concentrations that can reach hundreds of millimolar of phosphate units ${ }^{20}$. Due to this very high concentration, we expect polyP to outcompete the chelating compounds that limited the bioavailability of $\mathrm{Mg}^{2+}$ in the surrounding medium (Fig. 6c). The acidic $\mathrm{pH}$ of acidocalcisomes, which is around 5, and their high concentrations of basic amino acids and polyamines, should favor this competition. PolyP should hence sequester $\mathrm{Mg}^{2+}$ from the endocytosed fluid phase and concentrate it inside these organelles. Concentration is expected to facilitate its transfer to the vacuolar $\mathrm{Mg}^{2+}$ exporter, which then makes the metal available to the cytosol. We consider polyP essentially as an intracellular ion filter that extracts metal ions from a continuous flow of media through the vacuole, which is established by vesicular traffic to and from this organelle. This sets it apart from other strategies of metal acquisition such as siderophores, which are secreted into the extracellular space and then recovered by high-affinity transporters in the plasma membrane $e^{61}$.

An interesting open question is how $\mathrm{Mg}^{2+}$ that is accumulated through polyP inside vacuoles could become available for the vacuolar $\mathrm{Mg}^{2+}$-exporter. Several properties of polyP might be relevant for this, giving rise to the following hypotheses, which are not mutually exclusive: First, polyP is a highly charged polymer that can reach $50-100 \mathrm{kDa}$ and form gels. It binds $\mathrm{Mg}^{2+}$ and other metal ions. Its confinement inside acidocalcisome-like vacuoles, which are connected to the environment via vesicular import and export, is expected to create a Donnan equilibrium. Donnan equilibria are established when macromolecules with an affinity for small solutes are confined in a space that is connected to a solute reservoir through a semipermeable barrier, which allows solutes to pass but retains the macromolecules ${ }^{62}$. In the

Fig. 5 Metal limitation and endocytosis. a Lucifer yellow uptake assayed by microscopy. Cells were pre-cultured on YPD, then grown on YPD or YPD/EDTA for $2 \mathrm{~h}$, sedimented and resuspended in the same medium containing $2.3 \mathrm{mM}$ Lucifer yellow. After 75 min of incubation, the cells were washed 5 times with PBS and analyzed by fluorescence and differential interference contrast (DIC) microscopy. Cells depleted for ATP by NaN $/ \mathrm{NaF}_{3}$ treatment (1 mM each) were used as a negative control. Scale bar: $5 \mu \mathrm{m}$. Gray values of the fluorescence images have been inverted. $\mathbf{b}$ Lucifer yellow uptake quantified by flow cytometry. Cells were incubated with Lucifer yellow and washed as in (a). Their fluorescence was analyzed by flow cytometry. The left panel shows a representative histogram. The right panel shows Lucifer yellow content from four independent experiments. Whiskers represent minimum and maximum of all of the data, the bottom and the top of the box show first and third quartiles and the band inside the box the median. c Growth analysis of membrane trafficking mutants on YPD and YPD/EDTA was performed as in Fig. 4a. d ICP-MS analysis of Mg content in the endocytosis mutants vrp1 $\Delta$ and sac6 $\Delta$, grown on YPD/EDTA, was performed as in Fig. 3a. Values per cell and per culture volume are shown. e Growth analysis of retromer complex mutants on YPD and YPD/EDTA was performed as in Fig. 4a. b-e The results represent mean \pm SD of at least three independent experiments. Differences were evaluated using Student's $t$ test comparing (b) wild-type and vtc $4 \Delta$ cells $\pm 1 \mathrm{mM}$ EDTA at each time point, and (d) vtc $4 \Delta$ and $m n r 2 \Delta$ cells with wild-type at each time point; $n s$, non-significant, ${ }^{*} p \leq 0.05 ;{ }^{\star \star} p \leq 0.01 ;{ }^{\star \star \star} p \leq 0.005$ 

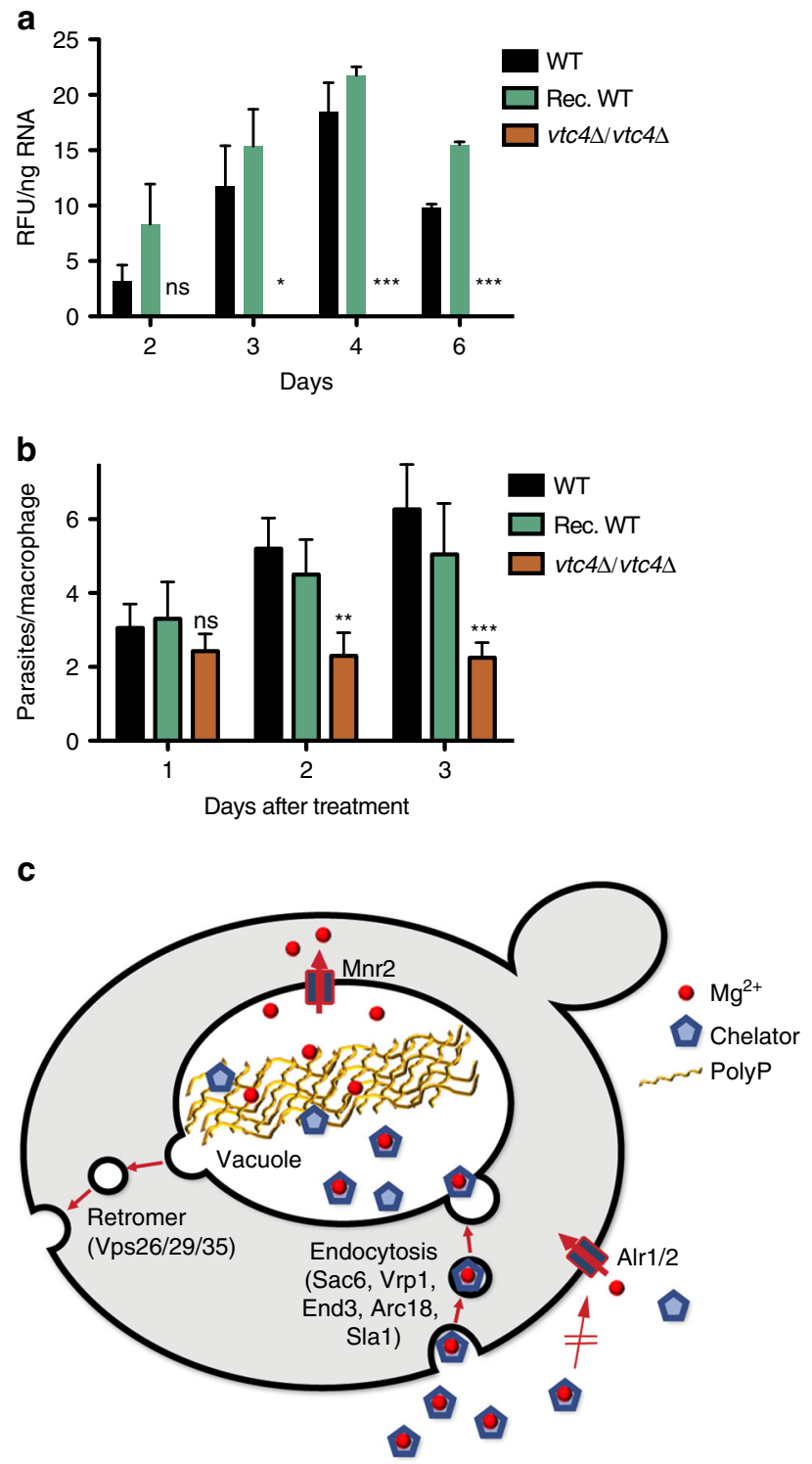

Fig. 6 PolyP and growth of Leishmania major in macrophages. a PolyP levels during promastigote growth. Promastigotes of wild-type, a double-knockout of LmVTC4 (vtc $4 \Delta / v t c 4 \Delta$ ) and of the double-knockout reconstituted with a wild-type allele of LmVTC4 (rec. WT) were inoculated in M199 medium. They were analyzed for their polyP content at the indicated times after inoculation. Day 4 corresponds to logarithmic growth, day 6 to stationary phase. $\mathbf{b}$ Proliferation inside macrophages. Bone-marrow-derived macrophages were infected with late stationary phase promastigotes. Microscopy pictures were taken 24,48 , and $72 \mathrm{~h}$ after infection and the number of amastigotes was counted in $>100$ macrophages per cell line. $\mathbf{a}, \mathbf{b}$ The results represent mean $\pm S D$. Statistical differences were evaluated using Student's $t$ test, comparing vtc $4 \Delta / v t c 4 \Delta$ with wild-type cells at each time point from 4 independent experiments: ns, nonsignificant; ${ }^{\star} p \leq 0.05 ;{ }^{* \star} p \leq 0.005 ;{ }^{* \star *} p \leq 0.0005$. c Working model of the EAPEC pathway. When cells cannot acquire sufficient amounts of free $\mathrm{Mg}^{2+}$ through their plasma membrane transporters (Alr1/2), they endocytose bulk fluid phase with chelated $\mathrm{Mg}^{2+}$ and transfer this solution into the acidocalcisome-like vacuole. Here, high concentrations of polyP, in combination with acidic $\mathrm{pH}$, favor liberation of the metal ions from chelating substances and their adsorption to polyP. This leads to the enrichment of $\mathrm{Mg}^{2+}$ inside vacuoles and facilitates its transport into the cytosol via the $\mathrm{Mg}^{2+}$ exporter Mnr2 case of the yeast cell, the confinement of polyP inside the vacuole, in combination with vesicular fluid-phase transport to and from this compartment, establishes the conditions for Donnan equilibria. The resulting elevated concentration of free $\mathrm{Mg}^{2+}$ in the vacuolar lumen would allow the vacuolar $\mathrm{Mg}^{2+}$ exporter to function more efficiently. Second, the vacuolar $\mathrm{Mg}^{2+}$ exporter might interact with polyP and take over bound $\mathrm{Mg}^{2+}$ directly. Third, polyP might be degraded inside vacuoles in order to liberate bound $\mathrm{Mg}^{2+}$. In line with this, mother cells, which continue to grow under limited metal availability and hence keep acquiring $\mathrm{Mg}^{2+}$, show shorter polyP fragments than the arrested daughters. If enzymatic hydrolysis of polyP occurred close to the vacuolar membrane, it might liberate $\mathrm{Mg}^{2+}$, preferentially for export. Unfortunately, the polyP degradation machinery of yeast vacuoles is poorly explored. Vacuoles contain at least three polyphosphatase activities. So far, only the membrane-associated Ppn2 $2^{63,64}$ and the soluble Ppn1 could be identified ${ }^{63}$, and their simultaneous deletion did not impair growth on YPD/ EDTA (not shown). Fourth, polyP readily associates with a variety of abundant cations. Arg, Lys, $\mathrm{K}^{+}$, and polyamines accumulate in vacuoles also in concentrations of tens to hundreds of millimolar, maintained by dedicated vacuolar importers ${ }^{65,66}$. They might compete with $\mathrm{Mg}^{2+}$ for binding polyP, facilitating $\mathrm{Mg}^{2+}$ release. Fifth, polyP forms gel phases that separate adsorbed molecules from the rest of the solution. These phase transitions depend on $\mathrm{pH}$, ionic strength and the type of metal ions bound ${ }^{67}$. Continuous active vacuolar import of counter-ions could maintain their concentrations higher in proximity to their importers, which might promote preferential liberation of $\mathrm{Mg}^{2+}$ close to the vacuolar membrane and the vacuolar $\mathrm{Mg}^{2+}$ exporter. At this point, these hypotheses cannot be tested because we lack techniques to assess the distributions of short- and long-chain polyP and of the mentioned organic and inorganic cations within vacuoles with sufficient spatial resolution.

Cells might employ metal acquisition via endocytosis and polyP also for acquiring metals other than $\mathrm{Mg}^{2+}$. We created experimental conditions that rendered $\mathrm{Mg}^{2+}$ limiting, permitting an analysis focused on this metal. However, fluid-phase endocytosis is non-selective and polyP can sequester a broad range of divalent and trivalent metal ions ${ }^{22}$. Vacuoles and acidocalcisomes also contain exporters for transferring a variety of metal ions into the cytosol. Therefore, it is possible that the same pathway and strategy that we identified here for $\mathrm{Mg}^{2+}$ might also be used to overcome limited availability of other metal ions. Furthermore, the EAPEC pathway might be conserved among different species because a key feature required for it, an acidocalcisome-like organelle rich in polyP and equipped with metal exporters, is found in all kingdoms of life $\mathrm{e}^{20}$. This is supported by our results on the proliferation of Leishmania in phagolysosomes of inflammatory macrophages. Proliferation of Leishmania in phagolysosomes is limited by $\mathrm{Mg}^{2+59}$ and depends on polyP. While during growth in rich media acidocalcisomes are not connected to endocytic traffic ${ }^{68-71}$, such a connection can be established in specific metabolic situations, which allows Leishmania acidocalcisomes to accumulate endocytic tracers ${ }^{72}$. Therefore, Leishmania might be able to induce the EAPEC pathway when proliferating inside macrophages. Also, Trypanosoma brucei, which causes sleeping sickness, depends on the polyP of its acidocalcisomes for virulence ${ }^{26}$, although in this case, it has not yet been tested whether metal acquisition contributes to the phenotype.

In sum, whereas acidocalcisome-like organelles have frequently been considered as simple storage compartments, our results ascribe to these organelles an active role in metal acquisition for the cytosol. They identify a novel pathway for metal acquisition that utilizes an inorganic intracellular polymer, polyP, as a crucial 
element. This inorganic polymer is constrained in a specialized organelle and connected to the environment through a flow of aqueous phase generated by endocytosis and vesicular retrograde traffic. It can hence be considered as an intracellular ion filter that is dedicated to extracting $\mathrm{Mg}^{2+}$, and perhaps other metal ions, from the environment, and facilitates their enrichment and transfer to the cytosol under conditions of limited bioavailability.

\section{Methods \\ Yeast strains and media. S. cerevisiae strains used in this study are listed in Supplementary Table 1. Knockout strains obtained from deletion collections were re-tested by PCR. Primer sequences are listed in Supplementary Table 2. Cells were cultivated overnight at $30{ }^{\circ} \mathrm{C}$ in YPD ( $1 \%$ yeast extract, $2 \%$ peptone, $2 \%$ glucose) to mid-exponential growth phase and inoculated in YPD supplemented with $1 \mathrm{mM}$ EDTA at $0.1 \mathrm{OD}$ units $\mathrm{ml}^{-1}$ (corresponds to $0.4 \times 10^{7}$ cells $\mathrm{ml}$ ). Since their ion content can vary moderately, new batches of yeast extract and peptone were routinely tested for the induction of a growth defect at an EDTA concentration of $1 \mathrm{mM}$. Metal-depleted YPD (YPD/Chelex) was prepared by incubating $5 \mathrm{~g}$ of Chelex-100 resin (Bio-Rad) per $100 \mathrm{ml}$ YPD overnight on a rotating wheel at $4{ }^{\circ} \mathrm{C}$. The resin was removed by filtration through a $0.2 \mu \mathrm{m}$ filter and the $\mathrm{pH}$ was adjusted to 7 with $1 \mathrm{~N} \mathrm{HCl}$. Residual metal concentrations of YPD/Chelex were determined by ICP-MS and are listed in Supplementary Table 3. \\ Parasite cell lines and media. L. major MRHO/IR/75/ER was used in this study. Promastigotes were grown at $26^{\circ} \mathrm{C}$ in M199 medium (Invitrogen AG) com- plemented with $10 \%$ heat-inactivated fetal bovine serum (FBS, Seromed), $50 \mathrm{U} \mathrm{ml}$ ${ }_{-1}^{-1}$ penicillin/streptomycin (Animed), $40 \mathrm{mM}$ Hepes (Animed), $0.6 \mathrm{mgl}^{-1}$ biopterin (Sigma) and $5 \mathrm{mgl}^{-1}$ hemin (Sigma).}

Constructs for LmVtc4 mutant cell lines. To target both LmjVTC4 alleles in the knockout cell line, plasmids based on the pX63-HYG vector ${ }^{73}$ were used. $787 \mathrm{bp}$ of the VTC4 3'-UTR were amplified from genomic DNA and cloned into the vector using SmaI and BglII restriction sites. $460 \mathrm{bp}$ of the $5^{\prime}$-UTR were amplified from genomic DNA and cloned into the HindIII and SalI sites to create pLmjVTC4.k.o.HYG. To generate pLmjVTC4.k.o.-PAC, the PAC gene was released by SpeI/ $B a m H I$ digestion from a modified pX63-PAC vector and used to replace the HYG gene in pLmjVTC4.k.o.-HYG ${ }^{74}$. Both plasmids were digested with BglII/ HindII and the knockout cassettes gel-purified (Promega) and used for parasite transfection. Gene replacements were verified by PCR and Southern blotting.

VTC4 was genomically integrated and re-expressed in the L. major $v t c 4 \Delta / v t c 4 \Delta$ cell line by replacing the HYG resistance gene of the pSSU-int construct ${ }^{60}$ with NEO (from pX63-NEO) using SpeI and XbaI. LmjVTC4 was amplified from genomic DNA and cloned into the vector using ClaI and XmaI. The intergenic region of cysteine proteinase B (CPB) 2.8 was cloned in-between LmjVTC4 and NEO using XmaI/ SpeI. The transfection cassette of pSSU-LmjVTC4-NEO was excised by PacI/ PmeI digestion, gel-purified and used for parasite transfection. Gene integration was verified by PCR and protein synthesis by Western blotting.

Leishmania stable transfection. A concentration of 8-12 $\mu \mathrm{g}$ linear DNA in $5 \mu \mathrm{l}$ $\mathrm{H}_{2} 0$ was used to transfect $2 \times 10^{7}$ parasites. Parasites were centrifuged and washed with phosphate buffered saline (PBS). The pellet was resuspended in $100 \mu \mathrm{l} \mathrm{T}$-cell Nucleofection solution of the Amaxa human T-cell Nucleofector kit (Lonza) and the DNA was added. This mixture was transferred to the Amaxa cuvette and electroporated with the Nucleofector II device, program U-033. Cells were incubated at $26^{\circ} \mathrm{C}$ in $4 \mathrm{ml}$ complete M199 medium overnight. After $24 \mathrm{~h}$, cells were plated on semi-solid M199 media containing the appropriate drug to select clonal lines. Drug concentrations were $100 \mu \mathrm{g} \mathrm{ml}^{-1}$ hygromycin, $50 \mu \mathrm{g} \mathrm{ml}^{-1}$ puromycin and $25 \mu \mathrm{g} \mathrm{ml}^{-1}$ neomycin. Colonies were recovered from the plates after $10-15$ days.

Cell viability assays. To determine the number of colony-forming units (CFU), strains were cultured overnight in YPD to mid-exponential growth phase and transferred to YPD with $1 \mathrm{mM}$ EDTA. $0.25 \mathrm{OD}_{600 \mathrm{~nm}}$ units were collected, pelleted and re-suspended in $250 \mu \mathrm{l} \mathrm{H} \mathrm{H}_{2} \mathrm{O}$. A 10x dilution series was prepared and spread on YPD plates. Colonies were counted after 2 days of incubation at $30^{\circ} \mathrm{C}$. Dead cells were quantified by propidium iodide (PI) staining. $0.25 \mathrm{OD}_{600 \mathrm{~nm}}$ units were withdrawn from an YPD/EDTA culture. Cells were washed in $1 \times$ PBS and $3 \mu \mathrm{l}$ PI $\left(1 \mathrm{mg} \mathrm{ml}^{-1}\right)$ was added to $1 \mathrm{ml}$ of cell suspension in PBS. The suspension was incubated for $20 \mathrm{~min}$ in the dark at room temperature. Samples were cooled on ice and flow cytometry was performed within $1 \mathrm{~h}$. Fluorescence from 20,000 cells was acquired on a BD Accuri C6 flow cytometer. PI was excited at $488 \mathrm{~nm}$ and the fluorescence detected in the FL3 channel.

Bud scar analysis. A concentration of $0.6 \mathrm{OD}_{600} \mathrm{~nm}$ units were taken from a YPD culture in early logarithmic growth phase and cells were washed twice with 1x PBS/ $2 \%$ glucose. The pellet was resuspended in $500 \mu \mathrm{l} 1 \times \mathrm{PBS} / 2 \%$ glucose containing $2 \mathrm{mg}$ EZ-Link-Sulfo-NHS-LC-LC-Biotin (Invitrogen) and incubated for $30 \mathrm{~min}$ at $30^{\circ} \mathrm{C}$. Cells were washed 3 times with $1 \times \mathrm{PBS} / 2 \%$ glucose and resuspended in 480 $\mu \mathrm{l} 1 \times \mathrm{PBS} / 2 \%$ glucose. $20 \mu \mathrm{l}$ of a $5 \mathrm{mg} \mathrm{m}^{-1}$ fluorescein-conjugated-avidin solution (Thermo Fisher Scientific) was added and the suspension was incubated for $10 \mathrm{~min}$ at room temperature in the dark. Cells were washed 3 times with $1 \times \mathrm{PBS} / 2 \%$ glucose and transferred to YPD/EDTA. After $16 \mathrm{~h}, 1 \mathrm{OD}_{600 \mathrm{~nm}}$ unit of cells was pelleted and resuspended in $0.9 \mathrm{ml} \mathrm{H}_{2} \mathrm{O} .100 \mu \mathrm{l}$ of a $1 \mathrm{mg} \mathrm{ml}^{-1}$ Calcoflour white stock were added and incubated for $10 \mathrm{~min}$ at room temperature. Cells were washed 5 times with water and z-stacks were taken on a confocal spinning disc microscope.

Metal analysis. Culture volumes of $20 \mathrm{ml}$ were collected by centrifugation $(5 \mathrm{~min}$, $\left.3,200 \times g, 4^{\circ} \mathrm{C}\right)$ and cells were washed in TE buffer $(10 \mathrm{mM}$ Tris-HCl, $1 \mathrm{mM}$ EDTA, $\mathrm{pH}$ 8.0). The pellets were digested in screw-cap tubes overnight in $1 \mathrm{ml} 20 \%$ nitric acid at $95^{\circ} \mathrm{C}$. Debris was removed in two centrifugation steps $(10 \mathrm{~min}, 16,000 \times g)$ in a table top centrifuge and the supernatant was transferred to a fresh tube. ICPMS analysis was performed with an ELAN DRC II from Perkin Elmer.

PolyP extraction, quantification and gel electrophoresis. PolyP extraction from yeast and Leishmania for gel analysis was carried out as follows ${ }^{75}$. Two $\mathrm{OD}_{600} \mathrm{~nm}$ units were collected by centrifugation and the pellet was re-suspended in $250 \mu \mathrm{l}$ of LETS buffer (10 mM Tris pH 8.0, $0.1 \mathrm{M} \mathrm{LiCl}, 10 \mathrm{mM}$ EDTA, $0.5 \%$ SDS). $250 \mu \mathrm{l}$ acid phenol ( $\mathrm{pH}$ 5.2) was added and the suspension transferred to an Eppendorf tube containing $250 \mu$ glass beads. The tubes were vortexed for $5 \mathrm{~min}$ at $4{ }^{\circ} \mathrm{C}$ and centrifuged $\left(15000 \times g, 5 \mathrm{~min}, 4^{\circ} \mathrm{C}\right) .200 \mu \mathrm{l}$ of the aqueous phase was transferred to a phase lock gel tube (5 Prime) and extracted with an equal volume of $\mathrm{CHCl}_{3}$. The extracts were centrifuged $\left(3 \mathrm{~min}, 13,000 \times g, 4^{\circ} \mathrm{C}\right)$ and the upper phase transferred to a fresh tube. PolyP and RNA were precipitated by adding 2.5 volumes of ice-cold ethanol and centrifuged $\left(15 \mathrm{~min}, 21,000 \times g, 4^{\circ} \mathrm{C}\right)$. The supernatant was discarded and the pellet washed once in $300 \mu \mathrm{l}$ ice-cold $75 \%$ ethanol. The pellet was dissolved in $25 \mu \mathrm{l} \mathrm{H} \mathrm{H}_{2} \mathrm{O}$ after air-drying for $2 \mathrm{~h}$.

Quantification of this polyP was either carried out by Ppx1-mediated hydrolysis and malachite green assay ${ }^{76}$, or by fluorescence spectroscopy with DAPI: A 10x dilution of the polyP extract was prepared in $20 \mathrm{mM}$ Hepes (pH 6.8), $150 \mathrm{mM} \mathrm{KCl}$ buffer and further diluted by factors 50 and 100 in a black 96-well plate in buffer containing $20 \mathrm{mM}$ HEPES ( $\mathrm{pH} 6.8$ ), $150 \mathrm{mM} \mathrm{KCl}$ and $10 \mu \mathrm{M}$ DAPI. The plate was equilibrated for $10 \mathrm{~min}$ at room temperature. DAPI-PolyP fluorescence was acquired for $20 \mathrm{~min}$ at $420 \mathrm{~nm}$ excitation and $550 \mathrm{~nm}$ emission in a Gemini EM Fluorescence Microplate Reader (Molecular Devices). A standard curve was prepared with PolyP60. For separation of polyP chains by electrophoresis, 15-30 nmol polyP were treated with RNAse, DNAseI and (where indicated) with recombinantly expressed and purified ScPpx ${ }^{38}$ before samples were resolved on a polyacrylamide gel (acrylamide/bisacrylamide 19:1, Serva) in TBE. Gels were run overnight at $3 \mathrm{~mA}$ and $4{ }^{\circ} \mathrm{C}$ until the loading dye (30\% glycerol, $0.5 \%$ bromophenol blue, $1 \mathrm{mM}$ EDTA) front migrated to $\frac{1}{2}$ to $3 / 4$ of the gel. Gels were stained in buffer with DAPI (1.5 g l-1 Tris base, $2 \%$ glycerol, $7.2 \mu \mathrm{M}$ DAPI) for $45-60 \mathrm{~min}$ and destained in the same buffer without DAPI for 30-45 min. Gels were exposed on a UV transilluminator to induce photobleaching, after which pictures of the gel were taken.

PolyP quantification for time-course analysis of L. major promastigotes was performed as follows ${ }^{77}$. Cells were pelleted and washed with $50 \mathrm{mM}$ HEPES $(\mathrm{pH}$ 7.5). The pellet was resuspended in $400 \mu$ DAPI buffer (20 mM HEPES pH 6.8, $150 \mathrm{mM} \mathrm{KCl}, 10 \mu \mathrm{M}$ DAPI) and freeze-thawed by 5 successive passages of $2 \mathrm{~min}$ between liquid nitrogen and room temperature. After centrifugation, the pellet was diluted in DAPI buffer in a final volume of $200 \mu \mathrm{l}$ in a 96-well plate in duplicate and incubated for $10 \mathrm{~min}$ at room temperature. Fluorescence was measured in a Gemini EM Fluorescence Microplate Reader (Molecular Devices) at $\lambda_{\text {ex }}=420 \mathrm{~nm}$ and $\lambda_{\mathrm{em}}=550 \mathrm{~nm}$. Values were normalized using co-isolated RNA and corrected for background signal using the polyP-deficient $v t c 4 \Delta / v t c 4 \Delta$ cell line.

Microscopy. Images were taken with an UltraView Vox spinning disk confocal microscope (Perkin Elmer-Cetus) connected to an inverted microscope (Carl Zeiss) with a $100 \times$ oil immersion objective with a numerical aperture of 1.41 and a Hamamatsu C9100-50 camera (Hamamatsu, Japan). FM4-64 was excited at $561 \mathrm{~nm}$ and imaged using a 705W90 nm band pass filter. Lucifer yellow was exited at $406 \mathrm{~nm}$ and imaged using a 527W55 nm band pass filter. Calcofluor white was excited at $406 \mathrm{~nm}$ and imaged using a $445 \mathrm{~W} 60 \mathrm{~nm}$ band pass filter. GFP and fluorescein were excited at $488 \mathrm{~nm}$ and imaged using a $527 \mathrm{~W} 55$ band pass filter. Images were processed with ImageJ and Adobe Photoshop software.

Vacuole staining with FM4-64. Cells were grown overnight to early logarithmic phase in YPD and inoculated in YPD or YPD/EDTA. 0.25 OD units were stained with $10 \mu \mathrm{M}$ FM4-64 (in dimethyl sulfoxide) in $1 \mathrm{ml}$ of the respective medium for $30 \mathrm{~min}$ at $30^{\circ} \mathrm{C}$. Cells were washed twice, chased for $45 \mathrm{~min}$ at $30^{\circ} \mathrm{C}$ and analyzed with a confocal microscope.

Lucifer yellow internalization assay. A total of $0.25 \mathrm{OD}_{600 \mathrm{~nm}}$ units were removed from the culture, pelleted and resuspended in $90 \mu \mathrm{l}$ of the respective medium. Lucifer yellow was added from a $10 \times$ stock solution to a final concentration of $2.3 \mathrm{mM}$. Cells were incubated for $75 \mathrm{~min}$ at $30^{\circ} \mathrm{C}$ before the dye was removed by 5 
washes with $1 \times$ PBS. Fluorescence was acquired on a FACSCanto flow cytometer (Becton Dickinson) and analyzed using FlowJo software (Tree Star). Lucifer yellow was excited with the $403 \mathrm{~nm}$ laser and detected in the AmCyan channel (BP 525/20).

Macrophage infection. Bone marrow cells were obtained by flushing the femurs and tibias of naive female C57BL/6 mice (Harlan). The extracted cells were differentiated into bone marrow-derived macrophages (BMDM) for 5-7 days using complete DMEM supplemented with $\mathrm{L} 929$ conditioned media at $37^{\circ} \mathrm{C}^{78}$. Differentiated BMDM were cultured in DMEM medium supplemented with $1 \%$ penicillin/streptomycin, 10\% FCS and $10 \mathrm{mM}$ HEPES at $37^{\circ} \mathrm{C}$ and $5 \% \mathrm{CO}_{2}$ for $2-12 \mathrm{~h}$ before being infected with late stationary phase promastigotes at a ratio of 1:5 (macrophage: Leishmania). Macrophages were incubated with parasites for $6 \mathrm{~h}$ at $37^{\circ} \mathrm{C}$ on cell culture coverslips (Thermomanx) in 24-well plates (500'000 macrophages per well). Non-phagocytosed parasites were removed by 2 washes with $1 \times$ PBS and fresh DMEM medium was added to the wells. Cells were fixed after 24, 48, and $72 \mathrm{~h}$ with $4 \%$ PFA for 15-20 min and stained with Diff-Quik (Dade Behring). Phase contrast pictures were taken with a Leica microscope and the number of amastigotes quantified in $>100$ macrophages per cell line.

Data availability. All source data are available from the corresponding author upon request.

Received: 24 November 2016 Accepted: 24 October 2017

Published online: 01 December 2017

\section{References}

1. Boynton, P. J. \& Greig, D. The ecology and evolution of non-domesticated Saccharomyces species. Yeast 31, 449-462 (2014).

2. Scalbert, A. Antimicrobial properties of tannins. Phytochemistry 30, 3875-3883 (1991).

3. Cos, P. et al. Proanthocyanidins in health care: current and new trends. Curr. Med. Chem. 11, 1345-1359 (2004).

4. Rieuwerts, J. S., Thornton, I., Farago, M. E. \& Ashmore, M. R. Factors influencing metal bioavailability in soils: preliminary investigations for the development of a critical loads approach for metals. Chem. Spec. Bioavailab. 10, 61-75 (2015).

5. González-Guerrero, M., Escudero, V., Saéz, Á. \& Tejada-Jiménez, M. Transition metal transport in plants and associated endosymbionts: Arbuscular Mycorrhizal fungi and rhizobia. Front. Plant Sci. 7, 635 (2016).

6. Lesuisse, E., Simon-Casteras, M. \& Labbe, P. Siderophore-mediated iron uptake in Saccharomyces cerevisiae: the SIT1 gene encodes a ferrioxamine B permease that belongs to the major facilitator superfamily. Microbiology 144, 3455-3462 (1998).

7. Heymann, P., Ernst, J. F. \& Winkelmann, G. Identification of a fungal triacetylfusarinine $\mathrm{C}$ siderophore transport gene (TAF1) in Saccharomyces cerevisiae as a member of the major facilitator superfamily. Biometals 12, 301-306 (1999).

8. Heymann, P., Ernst, J. F. \& Winkelmann, G. A gene of the major facilitator superfamily encodes a transporter for enterobactin (Enb1p) in Saccharomyces cerevisiae. Biometals 13, 65-72 (2000).

9. Yun, C. W., Tiedeman, J. S., Moore, R. E. \& Philpott, C. C. Siderophore-iron uptake in saccharomyces cerevisiae. Identification of ferrichrome and fusarinine transporters. J. Biol. Chem. 275, 16354-16359 (2000).

10. Yun, C.-W. et al. Desferrioxamine-mediated Iron Uptake in Saccharomyces cerevisiae. J. Biol. Chem. 275, 10709-10715 (2000).

11. Citiulo, F. et al. Candida albicans scavenges host zinc via Pral during endothelial invasion. PLoS Pathog. 8, e1002777 (2012).

12. Moore, R. E., Kim, Y. \& Philpott, C. C. The mechanism of ferrichrome transport through Arn1p and its metabolism in Saccharomyces cerevisiae. PNAS 100, 5664-5669 (2003).

13. Froissard, M. et al. Trafficking of siderophore transporters in saccharomyces cerevisiae and intracellular fate of ferrioxamine B conjugates. Traffic $\mathbf{8}$, 1601-1616 (2007).

14. Weissman, Z., Shemer, R., Conibear, E. \& Kornitzer, D. An endocytic mechanism for haemoglobin-iron acquisition in Candida albicans. Mol. Microbiol. 69, 201-217 (2008).

15. Patel, N., Singh, S. B., Basu, S. K. \& Mukhopadhyay, A. Leishmania requires Rab7-mediated degradation of endocytosed hemoglobin for their growth. Proc. Natl Acad. Sci. USA 105, 3980-3985 (2008).

16. Li, L., Chen, O. S., McVey Ward, D. \& Kaplan, J. CCC1 is a transporter that mediates vacuolar iron storage in yeast. J. Biol. Chem. 276, 29515-29519 (2001).

17. MacDiarmid, C. W., Gaither, L. A. \& Eide, D. Zinc transporters that regulate vacuolar zinc storage in Saccharomyces cerevisiae. EMBO J. 19, 2845-2855 (2000)
18. Rees, E. M., Lee, J. \& Thiele, D. J. Mobilization of intracellular copper stores by the ctr2 vacuolar copper transporter. J. Biol. Chem. 279, 54221-54229 (2004).

19. Blaby-Haas, C. E. \& Merchant, S. S. Lysosome-related organelles as mediators of metal homeostasis. J. Biol. Chem. 289, 28129-28136 (2014).

20. Docampo, R., de Souza, W., Miranda, K., Rohloff, P. \& Moreno, S. N. J. Acidocalcisomes - conserved from bacteria to man. Nat. Rev. Microbiol. 3, 251-261 (2005).

21. Docampo, R. \& Moreno, S. N. J. Acidocalcisomes. Cell. Calcium 50, 113-119 (2011).

22. Van Wazer, J. R. \& Callis, C. F. Metal complexing by phosphates. Chem. Rev. 58, 1011-1046 (1958).

23. Momeni, A. \& Filiaggi, M. J. Comprehensive study of the chelation and coacervation of alkaline earth metals in the presence of sodium polyphosphate solution. Langmuir 30, 5256-5266 (2014).

24. Cramer, C. L. \& Davis, R. H. Polyphosphate-cation interaction in the amino acid-containing vacuole of Neurospora crassa. J. Biol. Chem. 259, 5152-5157 (1984).

25. Kim, K.-S., Rao, N. N., Fraley, C. D. \& Kornberg, A. Inorganic polyphosphate is essential for long-term survival and virulence factors in Shigella and Salmonella spp. PNAS 99, 7675-7680 (2002).

26. Lander, N., Ulrich, P. N. \& Docampo, R. Trypanosoma brucei vacuolar transporter chaperone 4 (TbVtc4) is an acidocalcisome polyphosphate kinase required for in vivo infection. J. Biol. Chem. 288, 34205-34216 (2013).

27. Smith, S. A. et al. Polyphosphate modulates blood coagulation and fibrinolysis. PNAS 103, 903-908 (2006)

28. Hothorn, M. et al. Catalytic core of a membrane-associated eukaryotic polyphosphate polymerase. Science 324, 513-516 (2009).

29. Desfougères, Y., Gerasimaitė, R. U., Jessen, H. J. \& Mayer, A. Vtc5, a novel subunit of the vacuolar transporter chaperone complex, regulates polyphosphate synthesis and phosphate homeostasis in yeast. J. Biol. Chem. 291, 22262-22275 (2016)

30. Ruotolo, R., Marchini, G. \& Ottonello, S. Membrane transporters and protein traffic networks differentially affecting metal tolerance: a genomic phenotyping study in yeast. Genome Biol. 9, R67 (2008).

31. Chesi, A., Kilaru, A., Fang, X., Cooper, A. A. \& Gitler, A. D. The role of the parkinson's disease gene PARK9 in essential cellular pathways and the manganese homeostasis network in yeast. PLoS ONE 7, e34178 (2012).

32. Rosenfeld, L. et al. The effect of phosphate accumulation on metal ion homeostasis in Saccharomyces cerevisiae. J. Biol. Inorg. Chem. 15, 1051-1062 (2010).

33. Uttenweiler, A., Schwarz, H., Neumann, H. \& Mayer, A. The vacuolar transporter chaperone (VTC) complex is required for microautophagy. Mol. Biol. Cell. 18, 166-175 (2007).

34. Saito, K., Ohtomo, R., Kuga-Uetake, Y., Aono, T. \& Saito, M. Direct labeling of polyphosphate at the ultrastructural level in Saccharomyces cerevisiae by using the affinity of the polyphosphate binding domain of Escherichia coli exopolyphosphatase. Appl. Environ. Microbiol. 71, 5692-5701 (2005).

35. Werner, T. P., Amrhein, N. \& Freimoser, F. M. Specific localization of inorganic polyphosphate (poly P) in fungal cell walls by selective extraction and immunohistochemistry. Fungal. Genet. Biol. 44, 845-852 (2007).

36. Urech, K., Dürr, M., Boller, T., Wiemken, A. \& Schwencke, J. Localization of polyphosphate in vacuoles of Saccharomyces-Cerevisiae. Arch. Microbiol. 116 275-278 (1978)

37. Tijssen, J. P., Beekes, H. W. \& Van Steveninck, J. Localization of polyphosphates in Saccharomyces fragilis, as revealed by 4',6-diamidino-2phenylindole fluorescence. Biochim. Biophys. Acta. 721, 394-398 (1982).

38. Gerasimaite, R., Sharma, S., Desfougères, Y., Schmidt, A. \& Mayer, A. Coupled synthesis and translocation restrains polyphosphate to acidocalcisome-like vacuoles and prevents its toxicity. J. Cell. Sci. 127, 5093-5104 (2014).

39. Ogawa, N., DeRisi, J. \& Brown, P. O. New components of a system for phosphate accumulation and polyphosphate metabolism in Saccharomyces cerevisiae revealed by genomic expression analysis. Mol. Biol. Cell. 11, 4309-4321 (2000).

40. Avraham, N., Soifer, I., Carmi, M. \& Barkai, N. Increasing population growth by asymmetric segregation of a limiting resource during cell division. Mol. Syst. Biol. 9, 656 (2013)

41. Sethuraman, A., Rao, N. N. \& Kornberg, A. The endopolyphosphatase gene: essential in Saccharomyces cerevisiae. PNAS 98, 8542-8547 (2001).

42. Wiesenberger, G. et al. Mg2+ deprivation elicits rapid $\mathrm{Ca} 2+$ uptake and activates $\mathrm{Ca} 2+/$ calcineurin signaling in Saccharomyces cerevisiae. Eukaryot. Cell. 6, 592-599 (2007).

43. MacDiarmid, C. W. \& Gardner, R. C. Overexpression of the Saccharomyces cerevisiae magnesium transport system confers resistance to aluminum ion. J. Biol. Chem. 273, 1727-1732 (1998).

44. Graschopf, A. et al. The yeast plasma membrane protein Alr1 controls $\mathrm{Mg} 2+$ homeostasis and is subject to $\mathrm{Mg} 2+$-dependent control of its synthesis and degradation. J. Biol. Chem. 276, 16216-16222 (2001). 
45. Bui, D. M., Gregan, J., Jarosch, E., Ragnini, A. \& Schweyen, R. J. The bacterial magnesium transporter CorA can functionally substitute for its putative homologue Mrs2p in the yeast inner mitochondrial membrane. J. Biol. Chem. 274, 20438-20443 (1999).

46. Gregan, J. et al. The mitochondrial inner membrane protein Lpe10p, a homologue of Mrs2p, is essential for magnesium homeostasis and group II intron splicing in yeast. Mol. Gen. Genet. 264, 773-781 (2001).

47. Cui, Y. et al. A novel mitochondrial carrier protein Mmel acts as a yeast mitochondrial magnesium exporter. Biochim. Biophys. Acta. 1853, 724-732 (2015).

48. Pisat, N. P., Pandey, A. \& MacDiarmid, C. W. MNR2 regulates intracellular magnesium storage in Saccharomyces cerevisiae. Genetics 183, 873-884 (2009).

49. Wiederkehr, A., Meier, K. D. \& Riezman, H. Identification and characterization of Saccharomyces cerevisiae mutants defective in fluid-phase endocytosis. Yeast 18, 759-773 (2001).

50. Seaman, M. N., McCaffery, J. M. \& Emr, S. D. A membrane coat complex essential for endosome-to-Golgi retrograde transport in yeast. J. Cell. Biol. 142, 665-681 (1998)

51. Balderhaar, H. J. K. et al. The Rab GTPase Ypt7 is linked to retromer-mediated receptor recycling and fusion at the yeast late endosome. J. Cell. Sci. 123, 4085-4094 (2010).

52. Arlt, H., Reggiori, F. \& Ungermann, C. Retromer and the dynamin Vps1 cooperate in the retrieval of transmembrane proteins from vacuoles. J. Cell. Sci. 128, 645-655 (2015)

53. Garcia-del Portillo, F., Foster, J. W., Maguire, M. E. \& Finlay, B. B. Characterization of the micro-environment of Salmonella typhimuriumcontaining vacuoles within MDCK epithelial cells. Mol. Microbiol. 6, 3289-3297 (1992).

54. Eriksson, S., Lucchini, S., Thompson, A., Rhen, M. \& Hinton, J. Unravelling the biology of macrophage infection by gene expression profiling of intracellular Salmonella enterica. Mol. Microbiol. 47, 103-118 (2003).

55. Mann, F. M., VanderVen, B. C. \& Peters, R. J. Magnesium depletion triggers production of an immune modulating diterpenoid in Mycobacterium tuberculosis. Mol. Microbiol. 79, 1594-1601 (2011).

56. Lavigne, J.-P., O'callaghan, D. \& Blanc-Potard, A.-B. Requirement of MgtC for Brucella suis intramacrophage growth: a potential mechanism shared by Salmonella enterica and Mycobacterium tuberculosis for adaptation to a lowMg2+ environment. Infect. Immun. 73, 3160-3163 (2005).

57. Docampo, R. \& Huang, G. Acidocalcisomes of eukaryotes. Curr. Opin. Cell. Biol. 41, 66-72 (2016).

58. Antoine, J. C., Prina, E., Lang, T. \& Courret, N. The biogenesis and properties of the parasitophorous vacuoles that harbour Leishmania in murine macrophages. Trends Microbiol. 6, 392-401 (1998).

59. Lanza, H. et al. Comparative effect of ion calcium and magnesium in the activation and infection of the murine macrophage by Leishmania major. Biol. Res. 37, 385-393 (2004).

60. Misslitz, A., Mottram, J. C., Overath, P. \& Aebischer, T. Targeted integration into a rRNA locus results in uniform and high level expression of transgenes in Leishmania amastigotes. Mol. Biochem. Parasit. 107, 251-261 (2000).

61. Haas, H. Molecular genetics of fungal siderophore biosynthesis and uptake: the role of siderophores in iron uptake and storage. Appl. Microbiol. Biotechnol. 62, 316-330 (2003)

62. Nguyen, M. K. \& Kurtz, I. Quantitative interrelationship between GibbsDonnan equilibrium, osmolality of body fluid compartments, and plasma water sodium concentration. J. Appl. Physiol. 100, 1293-1300 (2006).

63. Kumble, K. D. \& Kornberg, A. Endopolyphosphatases for long chain inorganic polyphosphate in yeast and mammals. J. Biol. Chem. 271, 27146-27151 (1996).

64. Gerasimaite, R. \& Mayer, A. Ppn2, a novel Zn(2+)-dependent polyphosphatase in the acidocalcisome-like yeast vacuole. J. Cell. Sci. 130, 1625-1636 (2017).

65. Wiemken, A. \& Dürr, M. Characterization of amino acid pools in the vacuolar compartment of Saccharomyces cerevisiae. Arch. Microbiol. 101, 45-57 (1974).

66. Tomitori, H. et al. Multiple polyamine transport systems on the vacuolar membrane in yeast. Biochem. J. 353, 681-688 (2001).

67. Cini, N. \& Ball, V. Polyphosphates as inorganic polyelectrolytes interacting with oppositely charged ions, polymers and deposited on surfaces: fundamentals and applications. Adv. Colloid. Interface. Sci. 209, 84-97 (2014).

68. Coppens, I., Baudhuin, P., Opperdoes, F. R. \& Courtoy, P. J. Role of acidic compartments in Trypanosoma brucei, with special reference to low-density lipoprotein processing. Mol. Biochem. Parasit. 58, 223-232 (1993).

69. Scott, D. A., Docampo, R., Dvorak, J. A., Shi, S. \& Leapman, R. D. In situ compositional analysis of acidocalcisomes in Trypanosoma cruzi. J. Biol. Chem. 272, 28020-28029 (1997).
70. Mullin, K. A. et al. Regulated degradation of an endoplasmic reticulum membrane protein in a tubular lysosome in Leishmania mexicana. Mol. Biol. Cell. 12, 2364-2377 (2001).

71. Huang, G. et al. Adaptor protein-3 (AP-3) complex mediates the biogenesis of acidocalcisomes and is essential for growth and virulence of Trypanosoma brucei. J. Biol. Chem. 286, 36619-36630 (2011).

72. Vannier-Santos, M. A. et al. Impairment of sterol biosynthesis leads to phosphorus and calcium accumulation in Leishmania acidocalcisomes. Microbiology 145 (Pt 11), 3213-3220 (1999).

73. Cruz, A., Coburn, C. M. \& Beverley, S. M. Double targeted gene replacement for creating null mutants. PNAS 88, 7170-7174 (1991).

74. Price, H. P. et al. Myristoyl-CoA:protein N-myristoyltransferase, an essential enzyme and potential drug target in kinetoplastid parasites. J. Biol. Chem. 278 7206-7214 (2003).

75. Azevedo, C., Livermore, T. \& Saiardi, A. Protein polyphosphorylation of lysine residues by inorganic polyphosphate. Mol. Cell. 58, 71-82 (2015).

76. Desfougères, Y., Neumann, H. \& Mayer, A. Organelle size control - increasing vacuole content activates SNAREs to augment organelle volume through homotypic fusion. J. Cell. Sci. 129, 2817-2828 (2016).

77. Kulakova, A. N. et al. Direct quantification of inorganic polyphosphate in microbial cells Using 4'-6-Diamidino-2-Phenylindole (DAPI). Environ. Sci. Technol. 45, 7799-7803 (2011).

78. Meerpohl, H. G., Lohmann Matthes, M. L. \& Fischer, H. Studies on the activation of mouse bone marrow-derived macrophages by the macrophage cytotoxicity factor (MCF). Eur. J. Immunol. 6, 213-217 (1976).

\section{Acknowledgements}

We thank Andrea Schmidt and Florence Prevel for assistance; Deborah F. Smith (Imperial College of Science, London, UK) for providing us with the pX63-HYG plasmid; Toni Aebischer (University of Tübingen, Germany) for the pSSU-int vector; and Toshikazu Shiba (Regenetiss Inc., Japan) for polyP60. Yeast strains DY1457 WT and alr $1 \Delta$ were kindly provided by David Eide (University of Wisconsin-Madison, USA) and DTY165 ctr2 $\Delta$ by Dennis J. Thiele (Duke University School of Medicine, Durham, USA) This work was supported by grants from the SNF (CRS115_170925 and FNS 3100A0144258) and the ERC (FP7-233458) to A.M., by grants from the SNF to N.F., and by EU COST Action CM0801 (SER C09.0045) to N.F. and A.M.

\section{Author contributions}

S.H.K.: Conceived and performed the experiments and interpreted the data. K.K. and N.F.: Contributed the Leishmania experiments. A.M.: Conceived the experiments and interpreted the data. All authors wrote and approved the manuscript.

\section{Additional information}

Supplementary Information accompanies this paper at doi:10.1038/s41467-017-01930-5

Competing interests: The authors declare no competing financial interests.

Reprints and permission information is available online at http://npg.nature.com/ reprintsandpermissions/

Publisher's note: Springer Nature remains neutral with regard to jurisdictional claims in published maps and institutional affiliations.

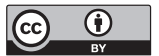

Open Access This article is licensed under a Creative Commons Attribution 4.0 International License, which permits use, sharing, adaptation, distribution and reproduction in any medium or format, as long as you give appropriate credit to the original author(s) and the source, provide a link to the Creative Commons license, and indicate if changes were made. The images or other third party material in this article are included in the article's Creative Commons license, unless indicated otherwise in a credit line to the material. If material is not included in the article's Creative Commons license and your intended use is not permitted by statutory regulation or exceeds the permitted use, you will need to obtain permission directly from the copyright holder. To view a copy of this license, visit http://creativecommons.org/ licenses/by/4.0/

(C) The Author(s) 2017 